\title{
Role of the multiple efflux pump protein TolC on growth, morphology, and biofilm formation under nitric oxide stress in Cronobacter malonaticus
}

Dengyu Liu, ${ }^{1}$ Yaping Wang, ${ }^{1}$ Xin Wang, ${ }^{1}$ Dexin Ou, ${ }^{1}$ Na Ling, ${ }^{1,2}$ Jumei Zhang, ${ }^{2}$ Qingping Wu, ${ }^{2}$ (]) and Yingwang $\mathrm{Ye}^{1,2 *}$ (1)

\section{Graphical Abstract}

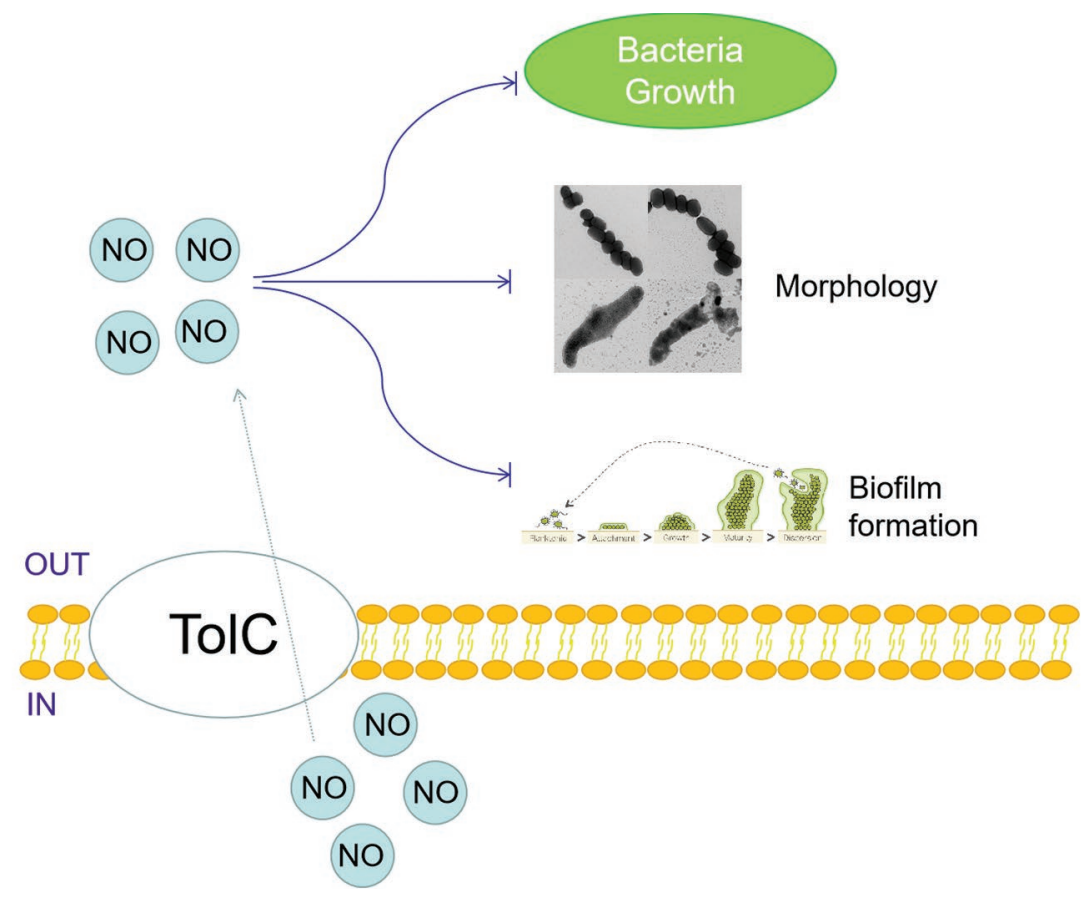

\section{Summary}

Cronobacter species are a group of gram-negative foodborne pathogens that cause severe diseases, including neonatal meningitis, septicemia, and necrotizing enterocolitis, especially in newborns and infants consuming contaminated powdered infant formula. In this study, we demonstrated that TolC, a protein component of a multidrug efflux pump in gram-negative bacteria, significantly contributes to tolerance to nitric oxide stress in Cronobacter malonaticus, providing a new perspective on prevention and control of infections caused by Cronobacter species.

\section{Highlights}

- Protein TolC contributes to tolerance to nitric oxide stress in Cronobacter malonaticus.

- Nitric oxide could inhibit the growth of Cronobacter malonaticus.

- Nitric oxide morphologically damaged Cronobacter malonaticus.

- Nitric oxide had a negative effect on biofilm formation by Cronobacter malonaticus.

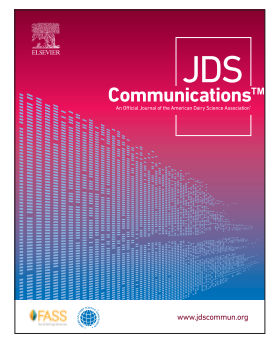

\footnotetext{
${ }^{1}$ School of Food and Biological Engineering, Hefei University of Technology, Hefei, 230009, China, ${ }^{2}$ Guangdong Provincial Key Laboratory of Microbial Culture Collection and Application, State Key Laboratory of Applied Microbiology Southern China, Guangdong Institute of Microbiology, Guangdong Academy of Sciences, Guangzhou, 510070, China. *Corresponding author: yeyw04@mails.ucas.ac.cn. @ 2021, The Authors. Published by Elsevier Inc. and Fass Inc. on behalf of the American Dairy Science Association ${ }^{\circledast}$. This is an open access article under the CC BY license (http://creativecommons.org/licenses/ by/4.0/). Received October 19, 2020. Accepted January 19, 2021.
} 


\title{
Role of the multiple efflux pump protein ToIC on growth, morphology, and biofilm formation under nitric oxide stress in Cronobacter malonaticus
}

\author{
Dengyu Liu, ${ }^{1}$ Yaping Wang, ${ }^{1}$ Xin Wang, ${ }^{1}$ Dexin Ou, ${ }^{1}$ Na Ling, ${ }^{1,2}$ Jumei Zhang, ${ }^{2}$ Qingping Wu, ${ }^{2}$ (1) \\ and Yingwang $\mathrm{Ye}^{1,2 *}$ (0)
}

\begin{abstract}
Nitric oxide (NO) is a biological signal molecule that can control and prevent the growth of most pathogens. Cronobacter species are a group of gram-negative foodborne pathogens that cause severe diseases, including neonatal meningitis, septicemia, and necrotizing enterocolitis, especially among newborns and infants consuming contaminated powdered infant formula. Cronobacter species might be tolerant to NO, resulting in severe infections. However, the specific mechanism of tolerance to NO in Cronobacter species is unclear. Here, we explore the effects of a key component, the protein TolC, of a multiple efflux pump on the growth, morphological changes, and biofilm formation of Cronobacter malonaticus under NO stress. We found that deletion of tolC resulted in a decreased growth rate under $100 \mathrm{~m} M$ sodium nitroprusside (NO donor) and led to more disruptive morphological injury to the bacterial cells. Furthermore, $C$. malonaticus lacking the TolC protein ( $\triangle$ tolC mutant) showed weaker biofilm formation than the wild-type strain under normal or NO stress conditions. We have proved that TolC plays an important role in cell growth and biofilm formation of C. malonaticus. Therefore, our results may provide valuable theoretical basis for formulating clinical guidelines for treatment of disease caused by C. malonaticus and ensuring food safety.
\end{abstract}

\begin{abstract}
Crono ronobacter species are opportunistic pathogens associated with severe diseases in neonates, including necrotizing enterocolitis, bacteremia, meningitis, and brain abscess or lesions (Bowen and Braden, 2006; Drudy et al., 2006). Cronobacter can be divided into 7 species: C. sakazakii, C. turicensis, C. muytjensii, C. dublinensis, C. universalis, C. condiment, and C. malonaticus (Iversen et al., 2008; Joseph et al., 2012). Cronobacter malonaticus can be isolated from clinical samples and different matrices such as infant formula, retail foods, and environmental samples (Fei et al., 2015; Killer et al., 2015; Brandão et al., 2017). Therefore, it is important to understand the molecular mechanism underlying virulence and tolerance of Cronobacter spp. to adverse stress to reduce its negative effects.

Nitric oxide (NO) is a gaseous signal molecule with multiple functions in humans, including involvement in the human immune system (Urbano et al., 2018). In the immune system, NO is usually produced by inducible nitric oxide synthase (iNOS), and its production is transcriptionally induced by upregulation of iNOS in response to cytokines and microbial products (Bogdan, 2015). During microbial pathogenic infection, high output of NO produced by iNOS can dramatically alter microbial metabolism and physiology (MacMicking et al., 1997; Fang, 2004; Lee et al., 2017).

To counter NO from the immune system, foodborne pathogens use a variety of detoxification systems, including detoxification genes and efflux pumps (Blair et al., 2015). The multidrug efflux pump AcrAB-TolC is present in gram-negative bacteria, and it reduces susceptibility to antimicrobial agents such as colicin E1,
\end{abstract}

hemolysin, and enterotoxins (Mu et al., 2020). In this efflux pump, TolC is an envelope protein, which was named because its loss by mutation conferred tolerance to specific colicins and bacteriophage (Koronakis et al., 2004). TolC plays vital roles in many gram-negative bacteria, such as Salmonella (Raspoet et al., 2019), Escherichia coli (Thanassi et al., 1997), Klebsiella pneumoniae (Iyer et al., 2019), and Enterobacter aerogenes (Masi et al., 2007). Although TolC exists in all 7 major species of Cronobacter, no research has characterized the functions of TolC in Cronobacter spp.

As a major antimicrobial substance, $\mathrm{NO}$ has been widely studied in bacteria. To date, little information is available about the roles of TolC in C. malonaticus. In this study, we investigated the roles of TolC when C. malonaticus is under stress from NO. We determined the growth conditions, morphological changes, and biofilm formation between wild type (WT) C. malonaticus and a mutant strain of C. malonaticus with deletion of the TolC protein ( $\Delta$ tolC mutant) under sodium nitroprusside (Snp), a nonenzymatic source of NO.

The WT and $\triangle$ tolC strains of C. malonaticus were acquired from the Guangdong Microbiology Culture Center (GDMCC; Guangzhou, China). Both strains were routinely grown in Luria-Bertani (LB) broth medium (Huankai) overnight at $37^{\circ} \mathrm{C}$, with agitation at $200 \mathrm{rpm}$ for $16 \mathrm{~h}$ to prepare the cells for each experiment.

Overnight cultures of $C$. malonaticus WT and $\triangle t o l C$ were diluted 100 -fold into $5 \mathrm{~mL}$ of LB and $5 \mathrm{~mL}$ of LB with $100 \mathrm{~m} M \mathrm{Snp}$ (Guangzhou Chemical Reagent Factory). Then, $200 \mu \mathrm{L}$ of diluted cultures were added to $96-$-well plates, and the plates were incu-

\footnotetext{
${ }^{1}$ School of Food and Biological Engineering, Hefei University of Technology, Hefei, 230009, China, ${ }^{2}$ Guangdong Provincial Key Laboratory of Microbial Culture Collection and Application, State Key Laboratory of Applied Microbiology Southern China, Guangdong Institute of Microbiology, Guangdong Academy of Sciences, Guangzhou, 510070, China. *Corresponding author: yeyw04@mails.ucas.ac.cn. @ 2021, The Authors. Published by Elsevier Inc. and Fass Inc. on behalf of the American Dairy Science Association ${ }^{\circledast}$. This is an open access article under the CC BY license (http://creativecommons.org/licenses/ by/4.0/). Received October 19, 2020. Accepted January 19, 2021.
} 
bated in a Cytation5 Cell Imaging Multi-Mode Reader (Biotek) with agitation at $200 \mathrm{rpm}$ for $24 \mathrm{~h}$. Absorbance was measured by optical density (OD) at $600 \mathrm{~nm}\left(\mathrm{OD}_{600}\right)$ every $30 \mathrm{~min}$.

To detect the relative change in cell number, strains were incubated in LB and LB with $100 \mathrm{~m} M$ Snp, respectively, at $37^{\circ} \mathrm{C}$, with shaking at $200 \mathrm{rpm}$, for $0.5,1.5$, and $2.5 \mathrm{~h}$. The number of cells of the 2 strains at each timepoint under different media was counted using a colony counting method. The relative change in cell number was calculated as the number of cells in the LB broth divided by the number of cells in the cultures with $100 \mathrm{mM}$ Snp. Each experiment was done in triplicate.

The strains were incubated in LB and LB with $100 \mathrm{mM}$ Snp, and the cells were harvested to detect morphologic changes using transmission electron microscopy (model S-3000N; Hitachi). The treatment procedure was performed according that described by Wang et al. (2013).

For detection of biofilms by crystal violet staining (CVS) assay, overnight cultures of the 2 strains were diluted 100 -fold into fresh LB and LB with $100 \mathrm{~m} M$ Snp. Then, $200 \mu \mathrm{L}$ of diluted culture was added to 96 -well plates, and the plates were incubated at $37^{\circ} \mathrm{C}$ for 24,48 , and $72 \mathrm{~h}$. The plates were then washed 3 times with sterile saline to remove planktonic bacteria, and the adherent bacterial cells were stained with $1 \%$ crystal violet for $30 \mathrm{~min}$. After being washed 3 times with sterile saline, the crystal violet was liberated by $33 \%$ acetic acid following a $15-\mathrm{min}$ incubation. The OD values of each well were measured at $590 \mathrm{~nm}$. Each experiment was done in triplicate.

For scanning electron microscopy, glass coverslips were placed into 24-well plates containing $1.98 \mathrm{~mL}$ of LB or LB with $100 \mathrm{mM}$ Snp. Then, $20 \mu \mathrm{L}$ of overnight culture of each strain was added to wells in a 24 -well plate and incubated at $37^{\circ} \mathrm{C}$ for 24,48 , and $72 \mathrm{~h}$. The glass coverslips from different incubation times were prepared for scanning electron microscopy, as described by Wang et al. (2013).

For confocal laser scanning microscopy (CLSM), glass coverslips were prepared in the same manner as for scanning electron microscopy, and bacterial biofilms on glass slips were stained using the LIVE/DEAD BacLight bacterial viability kit according to the manufacturer's instructions (Invitrogen/Thermo Fisher Scientific), and were then observed by CLSM.

Cronobacter spp. can tolerate different environmental stresses, such as acid, desiccation, and osmotic and oxidative stress (Yang et al., 2015; Zhang et al., 2018, 2019; Zhou et al., 2020). In this study, we first investigated the tolerance of $C$. malonaticus to NO stress. As shown in Figure 1 (A, B), Snp inhibited the growth of both the WT and $\triangle$ tolC strains of $C$. malonaticus. Nitric oxide, a key molecule produced by the immune system in mammals, is reported to control the growth of different types of bacteria, including Pseu-
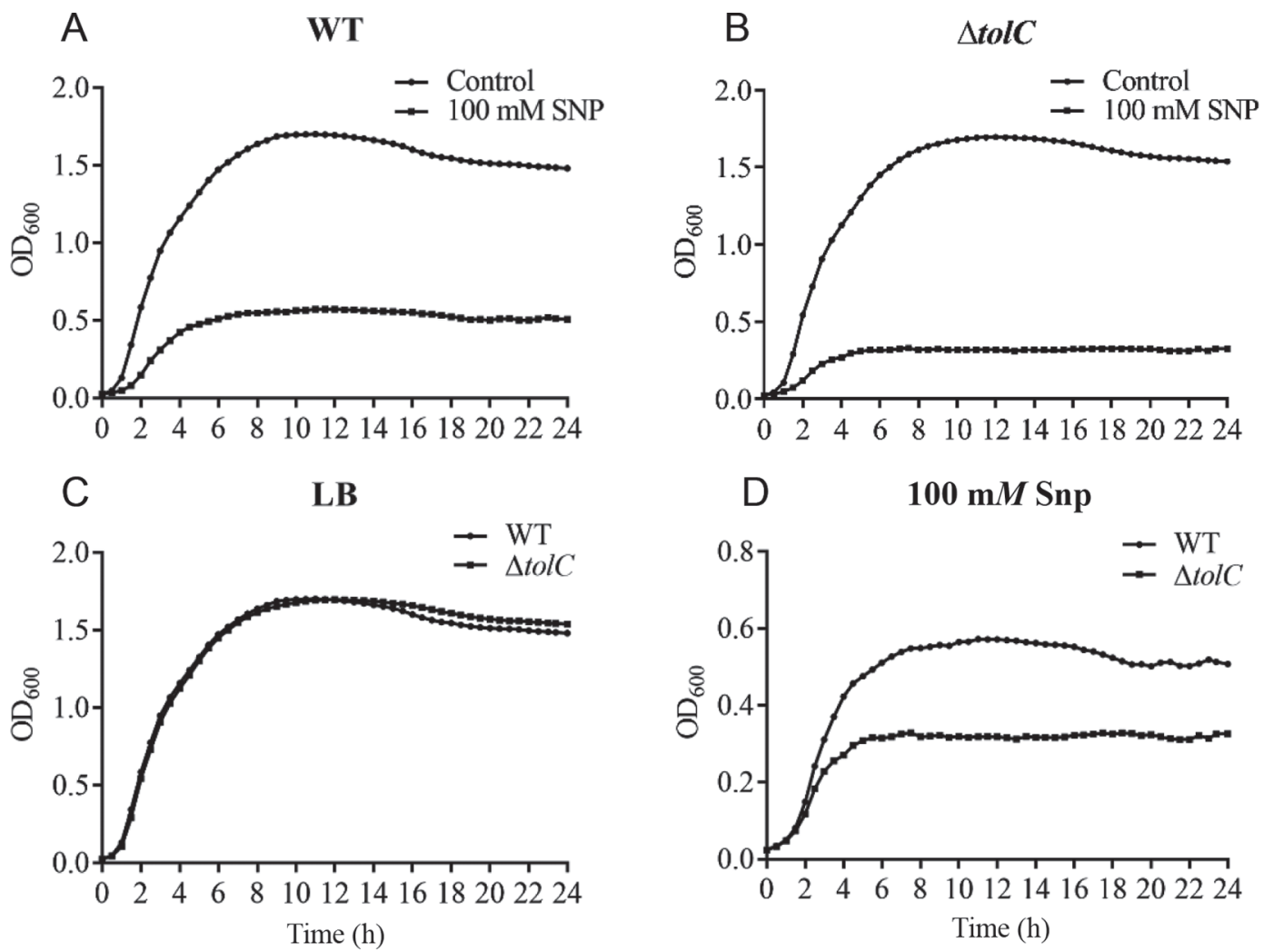

Figure 1. Growth curves (measured as optical density at $600 \mathrm{~nm}$ ) of (A) Cronobacter malonaticus wild type (WT), and (B) C. malonaticus with deletion of the multiple efflux pump protein TolC ( $\Delta$ tolC mutant) under $100 \mathrm{mM}$ sodium nitroprusside (Snp) stress. Comparison of growth curves of 2 strains in (C) LuriaBertani (LB) broth and (D) LB broth with $100 \mathrm{mM}$ Snp. (E) Relative change in cell number was calculated as the number of cells in the LB broth divided by the number of cells in the cultures with $100 \mathrm{mM}$ Snp for $0.5,1.5$, and $2.5 \mathrm{~h}$, respectively. Error bars indicate standard deviations. Asterisks indicate difference between WT and mutant at ${ }^{*} P<0.05$. 
domonas aeruginosa (Hibbard and Reynolds, 2019), Escherichia coli (Sivaloganathan and Brynildsen, 2020), and Staphylococcus aureus (Urbano et al., 2018). Moreover, NO has been shown to protect microorganisms from harmful reactive oxygen species produced by the immune system or various antibiotics (Gusarov and Nudler, 2005; Gusarov et al., 2009). In the current study, we found no difference between WT and $\triangle$ tolC C. malonaticus in LB broth (no Snp; Figure 1C), but the WT strain grew better than the $\triangle$ tolC strain in LB broth with $100 \mathrm{~m} M$ Snp (Figure 1D). Furthermore, as shown in Figure 1E, the relative change in cell number of WT and $\triangle$ tolC C. malonaticus treated with $100 \mathrm{~m} M$ Snp over $0.5,1.5$, and $2.5 \mathrm{~h}$ were $58.28 \pm 3.95 \%$ and $55.15 \pm 2.38 \%, 14.05$ $\pm 1.01 \%$ and $8.35 \pm 0.31 \%$, and $6.57 \pm 0.48 \%$ and $0.83 \pm 0.10 \%$, respectively, compared with those in LB without Snp. The AcrABTolC multidrug efflux pump system is one mechanism leading to bacterial resistance to antibiotics in gram-negative bacteria (Krishnamoorthy et al., 2013). TolC (but not the other part of efflux pump system, AcrB) is essential for colonization of chicks with multidrug-resistant Salmonella enterica serotype Typhimurium, which indicates that TolC might be a better target than AcrB for the development of efflux pump inhibitors (Baucheron et al., 2005). Overexpressing tolC from an inducible plasmid in a low-level resistance mutant of $E$. coli resulted in a higher level of nitroxoline resistance (Puértolas-Balint et al., 2020). When treated with 100 $\mathrm{m} M$ Snp, both strains in that study showed morphological injuries, including cell lengthening and breaks in the cell membrane. In our study, injuries to cells were more severe in $\Delta$ tolC than in WT, as shown in Figure 2; cell integrity and cell membranes were heavily damaged in $\triangle t o l C$, whereas the cell membrane of WT was only slightly damaged. In Helicobacter pylori, NO caused a rapid and dose-dependent morphologic conversion of $H$. pylori from the replicating spiral form to the nonreplicating coccoid form (Cole et al., 1999). Our results suggest that TolC is essential for growth of C. malonaticus under NO stress.

Bacterial biofilms are a lifestage of some species in which cells are embedded in a self-produced matrix that is adherent to a surface (Flemming et al., 2016). In the food industry, biofilm formation is one of the critical factors in persistent contamination by foodborne pathogens (Ye et al., 2018). Biofilm forms a protective microbial barrier against various environmental stresses; thus, cells in biofilms are generally more resistant than planktonic cells to the same stressor or condition (Hall-Stoodley et al., 2004; Winkelströter et al., 2014). In this study, we assessed biofilm formation of strains by CVS assay, scanning electron microscopy, and CLSM. For CVS assay, biofilm formation by the WT strain was increased compared with that of the $\triangle t o l C$ strain under normal conditions (without stressors), and inactivation of tolC impaired biofilm formation. Biofilm formation by both strains was reduced significantly under $100 \mathrm{~m} M \mathrm{Snp}$, although biofilm formation by WT was greater than that by $\Delta t o l C$ when exposed to Snp (Figure $3 \mathrm{~A}, \mathrm{~B}, \mathrm{C})$. Nitric oxide has been reported to enhance or decrease biofilm formation in different bacteria at different concentrations. In $E$. coli, $500 \mathrm{n} M$ Snp could remove approximately $38 \%$ of biofilm, but the same concentration of Snp induced stronger dispersal of Vibrio cholerae and Bacillus licheniformis biofilm (Barraud et al., 2009). However, NO was shown to stimulate biofilm formation by controlling the levels of the bacterial secondary messenger cyclic diguanosine monophosphate (c-di-GMP) in Shewanella oneidensis (Plate and Marletta, 2012). In P. aeruginosa treated with low concentrations of Snp ( $25 \mathrm{n} M$ to $2.5 \mathrm{mM}$ ), biofilm formation was decreased, whereas a high concentration of Snp (25 $\mathrm{m} M$ ) enhanced biofilm formation (Barraud et al., 2006). In Vibrio harveyi, $50 \mathrm{n} M$ NO promoted biofilm formation (Henares et al., 2013). Likewise, NO can disrupt Staph. aureus biofilms at high concentrations $(125-1,000 \mu M)$ but enhance biofilm formation at lower concentrations (0.975-1.96 $\mu M$; Jardeleza et al., 2011). According to scanning electron microscopy (Figure 3E), biofilm did not form well after $24 \mathrm{~h}$ of incubation, and numerous planktonic cells were observed on the glass coverslip. The best ability to form biofilm by both strains occurred after culture for $48 \mathrm{~h}$. At this stage, cells were gathered into a mass and the biofilms were compact and tight. After $72 \mathrm{~h}$ of incubation, biofilms of C. malonaticus dispersed. Biofilms were disrupted and reverted to the planktonic state when treated with Snp. In addition, we found that biofilms of

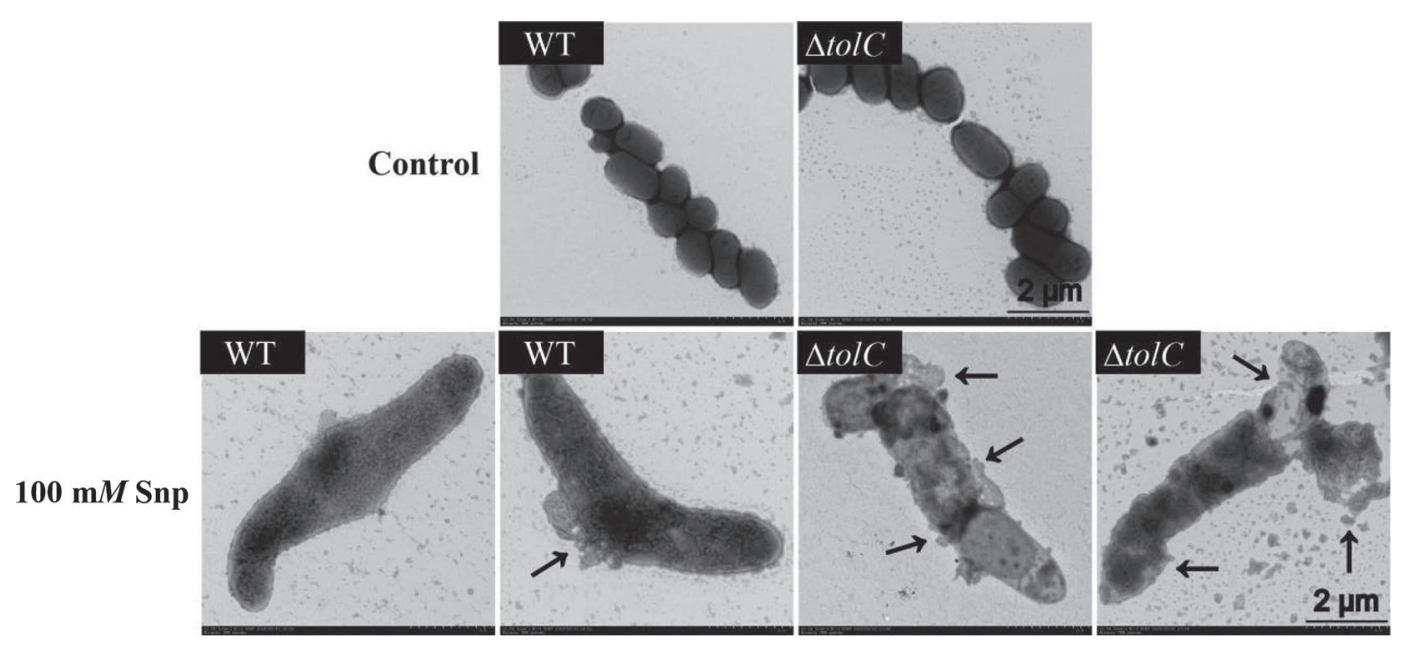

Figure 2. Morphological changes of Cronobacter malonaticus wild type (WT) and C. malonaticus with deletion of the multiple efflux pump protein TolC ( $\Delta$ tolC mutant) under sodium nitroprusside (Snp) stress using transmission electron microscopy. The arrows indicate the sites of morphological injury to the bacteria. 

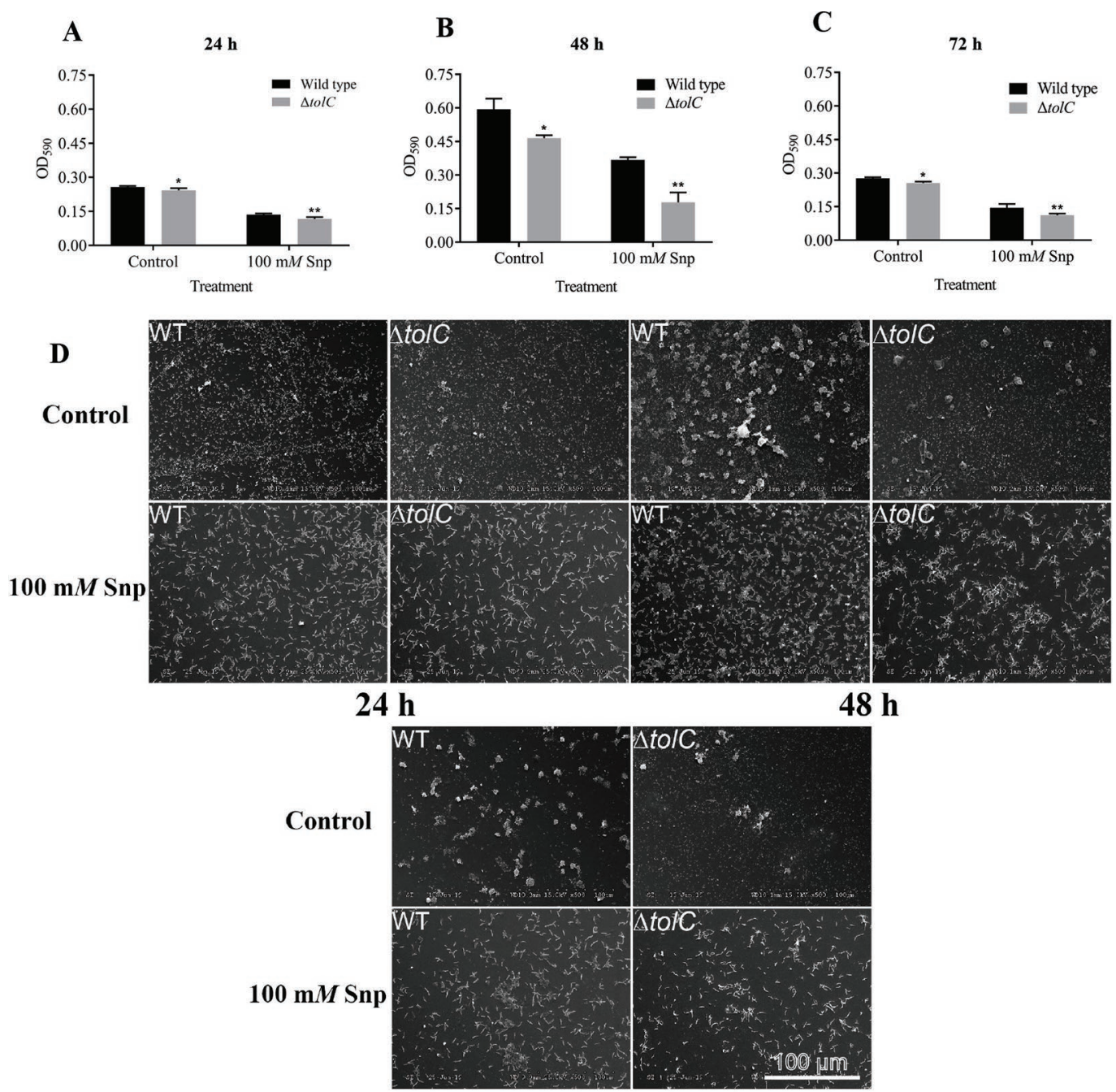

$72 \mathrm{~h}$

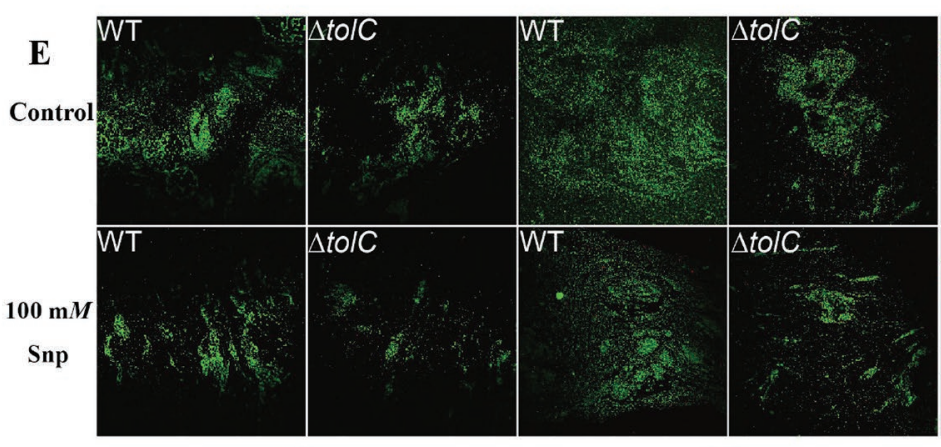

$24 \mathrm{~h}$
$48 \mathrm{~h}$

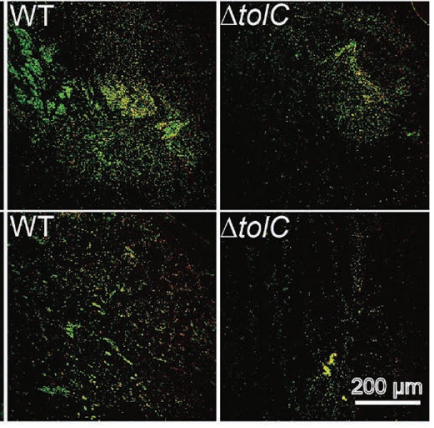

$72 \mathrm{~h}$

Figure 3. Biofilm formation by Cronobacter malonaticus wild type (WT) and C. malonaticus with deletion of the multiple efflux pump protein TolC ( $\Delta$ tolC mutant) under $100 \mathrm{mM}$ sodium nitroprusside (Snp) stress for (A) $24 \mathrm{~h}$, (B) $48 \mathrm{~h}$, and (C) $72 \mathrm{~h}$ using crystal violet staining assay, measured by optical density (OD) at $590 \mathrm{~nm}$. Error bars indicate standard deviations. Asterisks indicate difference between WT and mutant at ${ }^{*} P<0.05$ and ${ }^{* *} P<0.01$. Biofilm formation of $C$. malonaticus WT and $\triangle$ tolC under $100 \mathrm{mM}$ Snp stress for 24,48 , and $72 \mathrm{~h}$ using (D) scanning electron microscopy and (E) confocal laser scanning microscopy .

$\Delta$ tolC were weaker and looser than those of the WT strain under the same Snp concentration. As shown in Figure 3F, mature biofilms formed after $48 \mathrm{~h}$ of incubation, as shown by green staining under
CLSM. The numbers of dead cells (stained red) increased after 72 $\mathrm{h}$ in culture and were more prominent under treatment with 100 $\mathrm{m} M$ Snp than in the control group. As seen in the CVS assay and by 
scanning electron microscopy, biofilms of WT were stronger than those of $\triangle$ tolC under all circumstances. Bay et al. (2017) found that deletions of tolC resulted in significant reductions in biofilmforming phenotype and enhanced antimicrobial susceptibilities in E. coli. In Actinobacillus pleuropneumoniae, loss of TolC impaired biofilm formation by reducing cell surface hydrophobicity and autoaggregation during the process of initial attachment ( $\mathrm{Li}$ et al., 2016). Other types of efflux pump, such as MexAB-OprM of $P$. aeruginosa, AdeFGH of Acinetobacter baumannii, and AcrD of $S$. enterica, also play crucial roles in biofilm formation (Alav et al., 2018). Together, our results and the current literature suggest that TolC is a critical component of the efflux pump and essential to biofilm formation. Nitric oxide can affect growth of bacteria and biofilm formation depending on the species and the concentration of NO. In this study, we investigated the characteristics of TolC under NO stress in C. malonaticus through phenotypic analysis; the molecular mechanisms of TolC in C. malonaticus remain to be revealed.

\section{References}

Alav, I., J. M. Sutton, and K. M. Rahman. 2018. Role of bacterial efflux pumps in biofilm formation. J. Antimicrob. Chemother. 73:2003-2020. https://doi .org/10.1093/jac/dky042.

Barraud, N., D. J. Hassett, S. H. Hwang, S. A. Rice, S. Kjelleberg, and J. S. Webb. 2006. Involvement of nitric oxide in biofilm dispersal of Pseudomonas aeruginosa. J. Bacteriol. 188:7344-7353. https://doi.org/10.1128/ JB.00779-06.

Barraud, N., M. V. Storey, Z. P. Moore, J. S. Webb, S. A. Rice, and S. Kjelleberg. 2009. Nitric oxide-mediated dispersal in single- and multi-species biofilms of clinically and industrially relevant microorganisms. Microb. Biotechnol. 2:370-378. https://doi.org/10.1111/j.1751-7915.2009.00098.x.

Baucheron, S., C. Mouline, K. Praud, E. Chaslus-Dancla, and A. Cloeckaert. 2005. TolC but not AcrB is essential for multidrug-resistant Salmonella enterica serotype Typhimurium colonization of chicks. J. Antimicrob. Chemother. 55:707-712. https://doi.org/10.1093/jac/dki091.

Bay, D. C., C. A. Stremick, C. J. Slipski, and R. J. Turner. 2017. Secondary multidrug efflux pump mutants alter Escherichia coli biofilm growth in the presence of cationic antimicrobial compounds. Res. Microbiol. 168:208221. https://doi.org/10.1016/j.resmic.2016.11.003.

Blair, J. M. A., M. A. Webber, A. J. Baylay, D. O. Ogbolu, and L. J. V. Piddock. 2015. Molecular mechanisms of antibiotic resistance. Nat. Rev. Microbiol. 13:42-51. https://doi.org/10.1038/nrmicro3380.

Bogdan, C. 2015. Nitric oxide synthase in innate and adaptive immunity: An update. Trends Immunol. 36:161-178. https://doi.org/10.1016/j.it.2015.01 .003 .

Bowen, A. B., and C. R. Braden. 2006. Invasive Enterobacter sakazakii disease in infants. Emerg. Infect. Dis. 12:1185-1189. https://doi.org/10.3201/ eid1208.051509.

Brandão, M. L. L., N. S. Umeda, E. Jackson, S. J. Forsythe, and I. de Filippis. 2017. Isolation, molecular and phenotypic characterization, and antibiotic susceptibility of Cronobacter spp. from Brazilian retail foods. Food Microbiol. 63:129-138. https://doi.org/10.1016/j.fm.2016.11.011.

Cole, S. P., V. F. Kharitonov, and D. G. Guiney. 1999. Effect of nitric oxide on Helicobacter pylori morphology. J. Infect. Dis. 180:1713-1717. https://doi .org/10.1086/315079.

Drudy, D., N. R. Mullane, T. Quinn, P. G. Wall, and S. Fanning. 2006. Enterobacter sakazakii: An emerging pathogen in powdered infant formula. Clin. Infect. Dis. 42:996-1002. https://doi.org/10.1086/501019.

Fang, F. C. 2004. Antimicrobial reactive oxygen and nitrogen species: Concepts and controversies. Nat. Rev. Microbiol. 2:820-832. https://doi.org/ 10.1038/nrmicro1004

Fei, P., C. X. Man, B. B. Lou, S. J. Forsythe, Y. L. Chai, R. Li, J. T. Niu, and Y. J. Jiang. 2015. Genotyping and source tracking of Cronobacter sakazakii and $C$. malonaticus isolates from powdered infant formula and an infant formula production factory in China. Appl. Environ. Microbiol. 81:5430-5439. https://doi.org/10.1128/AEM.01390-15.
Flemming, H. C., J. Wingender, U. Szewzyk, P. Steinberg, S. A. Rice, and S. Kjelleberg. 2016. Biofilms: An emergent form of bacterial life. Nat. Rev. Microbiol. 14:563-575. https://doi.org/10.1038/nrmicro.2016.94.

Gusarov, I., and E. Nudler. 2005. NO-mediated cytoprotection: Instant adaptation to oxidative stress in bacteria. Proc. Natl. Acad. Sci. USA 102:1385513860. https://doi.org/10.1073/pnas.0504307102.

Gusarov, I., K. Shatalin, M. Starodubtseva, and E. Nudler. 2009. Endogenous nitric oxide protects bacteria against a wide spectrum of antibiotics. Science 325:1380-1384. https://doi.org/10.1126/science.1175439.

Hall-Stoodley, L., J. W. Costerton, and P. Stoodley. 2004. Bacterial biofilms: From the natural environment to infectious diseases. Nat. Rev. Microbiol. 2:95-108. https://doi.org/10.1038/nrmicro821.

Henares, B. M., Y. Xu, and E. M. Boon. 2013. A nitric oxide-responsive quorum sensing circuit in Vibrio harveyi regulates flagella production and biofilm formation. Int. J. Mol. Sci. 14:16473-16484. https://doi.org/10 .3390/ijms 140816473 .

Hibbard, H. A. J., and M. M. Reynolds. 2019. Fluorescent nitric oxide donor for the detection and killing of Pseudomonas aeruginosa. J. Mater. Chem. B Mater. Biol. Med. 7:2009-2018. https://doi.org/10.1039/C8TB02552E.

Iversen, C., N. Mullane, B. McCardell, B. D. Tall, A. Lehner, S. Fanning, R. Stephan, and H. Joosten. 2008. Cronobacter gen. nov., a new genus to accommodate the biogroups of Enterobacter sakazakii, and proposal of Cronobacter sakazakii gen. nov., comb. nov., Cronobacter malonaticus sp. nov., Cronobacter turicensis sp. nov., Cronobacter muytjensii sp. nov. Cronobacter dublinensis sp. nov., Cronobacter genomospecies 1, and of three subspecies, Cronobacter dublinensis ssp. dublinensis ssp. nov., Cronobacter dublinensis ssp. lausannensis ssp. nov. and Cronobacter dublinensis ssp. lactaridi ssp. nov. Int. J. Syst. Evol. Microbiol. 58:1442-1447. https://doi.org/10.1099/ijs.0.65577-0.

Iyer, R., S. H. Moussa, R. Tommasi, and A. A. Miller. 2019. Role of the Klebsiella pneumoniae TolC porin in antibiotic efflux. Res. Microbiol. 170:112-116. https://doi.org/10.1016/j.resmic.2018.11.003.

Jardeleza, C., A. Foreman, L. Baker, S. Paramasivan, J. Field, L. W. Tan, and P. J. Wormald. 2011. The effects of nitric oxide on Staphylococcus aureus biofilm growth and its implications in chronic rhinosinusitis. Int. Forum Allergy Rhinol. 1:438-444. https://doi.org/10.1002/alr.20083.

Joseph, S., H. Sonbol, S. Hariri, P. Desai, M. McClelland, and S. J. Forsythe. 2012. Diversity of the Cronobacter genus as revealed by multilocus sequence typing. J. Clin. Microbiol. 50:3031-3039. https://doi.org/10.1128/ JCM.00905-12.

Killer, J., E. Skrivanova, I. Hochel, and M. Marounek. 2015. Multilocus sequence typing of Cronobacter strains isolated from retail foods and environmental samples. Foodborne Pathog. Dis. 12:514-521. https://doi.org/10 $.1089 /$ fpd.2014.1884.

Koronakis, V., J. Eswaran, and C. Hughes. 2004. Structure and function of TolC: The bacterial exit duct for proteins and drugs. Annu. Rev. Biochem. 73:467-489. https://doi.org/10.1146/annurev.biochem.73.011303.074104.

Krishnamoorthy, G., E. B. Tikhonova, G. Dhamdhere, and H. I. Zgurskaya. 2013. On the role of TolC in multidrug efflux: The function and assembly of AcrABTolC tolerate significant depletion of intracellular TolC protein Mol. Microbiol. 87:982-997. https://doi.org/10.1111/mmi.12143.

Lee, M., K. Rey, K. Besler, C. Wang, and J. Choy. 2017. Immunobiology of nitric oxide and regulation of inducible nitric oxide synthase. Results Probl. Cell Differ. 62:181-207. https://doi.org/10.1007/978-3-319-54090-0 8.

Li, Y., S. Cao, L. Zhang, J. Yuan, G. W. Lau, Y. Wen, R. Wu, Q. Zhao, X. Huang, Q. Yan, Y. Huang, and X. Wen. 2016. Absence of TolC impairs biofilm formation in Actinobacillus pleuropneumoniae by reducing initial attachment. PLoS One 11:e0163364. https://doi.org/10.1371/journal.pone.0163364.

MacMicking, J., Q. W. Xie, and C. Nathan. 1997. Nitric oxide and macrophage function. Annu. Rev. Immunol. 15:323-350. https://doi.org/10.1146/ annurev.immunol.15.1.323.

Masi, M., N. Saint, G. Molle, and J. M. Pagès. 2007. The Enterobacter aerogenes outer membrane efflux proteins TolC and EeFC have different channel properties. Biochim. Biophys. Acta 1768:2559-2567. https://doi.org/10 .1016/j.bbamem.2007.06.008.

Mu, X. H., R. X. Gao, W. H. Xiao, Q. Q. Gao, C. G. Cao, H. Q. Xu, S. Gao, and X. F. Liu. 2020. EntE, EntS and TolC synergistically contributed to the pathogenesis of APEC strain E058. Microb. Pathog. 141:103990. https:// doi.org/10.1016/j.micpath.2020.103990. 
Plate, L., and M. A. Marletta. 2012. Nitric oxide modulates bacterial biofilm formation through a multicomponent cyclic-di-GMP signaling network. Mol. Cell 46:449-460. https://doi.org/10.1016/j.molcel.2012.03.023.

Puértolas-Balint, F., O. Warsi, M. Linkevicius, P. C. Tang, and D. I. Andersson. 2020. Mutations that increase expression of the EmrAB-TolC efflux pump confer increased resistance to nitroxoline in Escherichia coli. J. Antimicrob. Chemother. 75:300-308. https://doi.org/10.1093/jac/dkz434.

Raspoet, R., V. Eeckhaut, K. Vermeulen, L. De Smet, Y. Wen, K. Nishino, F. Haesebrouck, R. Ducatelle, B. Devreese, and F. Van Immerseel. 2019. The Salmonella Enteritidis TolC outer membrane channel is essential for egg white survival. Poult. Sci. 98:2281-2289. https://doi.org/10.3382/ps/ pey584.

Sivaloganathan, D. M., and M. P. Brynildsen. 2020. Quantitative modeling extends the antibacterial activity of nitric oxide. Front. Physiol. 11:330. https://doi.org/10.3389/fphys.2020.00330.

Thanassi, D. G., L. W. Cheng, and H. Nikaido. 1997. Active efflux of bile salts by Escherichia coli. J. Bacteriol. 179:2512-2518. https://doi.org/10.1128/ JB.179.8.2512-2518.1997.

Urbano, R., J. E. Karlinsey, S. J. Libby, P.-T. Doulias, H. Ischiropoulos, H. I. Warheit-Niemi, D. H. Liggitt, A. R. Horswill, and F. C. Fang. 2018 Host nitric oxide disrupts microbial cell-to-cell communication to inhibit staphylococcal virulence. Cell Host Microbe 23:594-606.e7. https://doi .org/10.1016/j.chom.2018.04.001.

Wang, C. Y., C. P. Hsu, H. W. Huang, and B. B. Yang. 2013. The relationship between inactivation and morphological damage of Salmonella enterica treated by high hydrostatic pressure. Food Res. Int. 54:1482-1487. https:// doi.org/10.1016/j.foodres.2013.08.004.

Winkelströter, L. K., F. B. D. Teixeira, E. P. Silva, V. F. Alves, and E. C. P. de Martinis. 2014. Unraveling microbial biofilms of importance for food microbiology. Microb. Ecol. 68:35-46. https://doi.org/10.1007/s00248 $-013-0347-4$.

Yang, H.-Y., S.-K. Kim, S.-Y. Choi, D.-H. You, S.-C. Lee, W.-S. Bang, and H.G. Yuk. 2015. Effect of acid, desiccation and heat stresses on the viability of Cronobacter sakazakii during rehydration of powdered infant formula and in simulated gastric fluid. Food Control 50:336-341. https://doi.org/10 1016/j.foodcont.2014.09.012.

Ye, Y., N. Ling, J. Gao, X. Zhang, M. Zhang, L. Tong, H. Zeng, J. Zhang, and Q. Wu. 2018. Roles of outer membrane protein W (OmpW) on survival, morphology, and biofilm formation under $\mathrm{NaCl}$ stresses in Cronobacter sakazakii. J. Dairy Sci. 101:3844-3850. https://doi.org/10.3168/jds.2017 $-13791$.

Zhang, M., X. Zhang, L. Tong, D. Ou, Y. Wang, J. Zhang, Q. Wu, and Y. Ye. 2019. Random mutagenesis applied to reveal factors involved in oxidative tolerance and biofilm formation in foodborne Cronobacter malonaticus. Front. Microbiol. 10:877. https://doi.org/10.3389/fmicb.2019.00877.

Zhang, M., X. Zhang, L. Tong, Y. Wang, D. Ou, J. Zhang, Q. Wu, and Y. Ye. 2018. Genes involved in tolerance to osmotic stress by random mutagenesis in Cronobacter malonaticus. J. Dairy Sci. 101:3851-3858. https://doi .org/10.3168/jds.2017-13995.

Zhou, A., Y. Cao, D. Zhou, S. Hu, W. Tan, X. Xiao, Y. Yu, and X. Li. 2020 Global transcriptomic analysis of Cronobacter sakazakii CICC 21544 by RNA-seq under inorganic acid and organic acid stresses. Food Res. Int. 130:108963. https://doi.org/10.1016/j.foodres.2019.108963.

\section{Notes}

Qingping Wu (1) https://orcid.org/0000-0002-8861-7456

Yingwang Ye (D) https://orcid.org/0000-0002-5604-8711

We gratefully acknowledge the financial support of the National Key Research and Development program, China (2017YFC1601200), the financial support of the National Natural Science Foundation of China, China (31671951), Local Innovative and Research Teams Project of Guangdong PEARL River Talents Program (2017BT01S174), the Science and Technology Planning Project of Guangdong Province, Guangdong Province (2016A050502033), Project of Science and Technology in Guangzhou (201604020036), Fundamental Research Funds for the Central Universities, China (JZ2020YYPY0252).

The authors have not stated any conflicts of interest. 